Pacific Journal of Mathematics

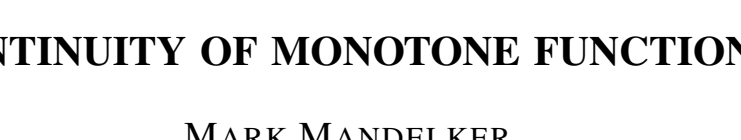




\title{
CONTINUITY OF MONOTONE FUNCTIONS
}

\author{
MARK MANDELKERN
}

Two refractory problems in modern constructive analysis concern real-valued functions on the closed unit interval: Is every function pointwise continuous? Is every pointwise continuous function uniformly continuous? For monotone functions, some answers are given here. Functions which satisfy a certain strong monotonicity condition, and approximate intermediate values, are pointwise continuous. Any monotone pointwise continuous function is uniformly continuous. Continuous inverse functions are also obtained. The methods used are in accord with the principles of Bishop's Foundations of Constructive Analysis, 1967.

Introduction. Consider two statements concerning real-valued functions on the closed unit interval:

(i) Every function is pointwise continuous.

(ii) Every pointwise continuous function is uniformly continuous.

Classically (that is, nonconstructively, with the aid of the principle of excluded middle), the first statement is of course false, and the second true. However, since Brouwer's critique of classical mathematics, both have been open problems in constructive analysis. Here we consider these problems for the class of monotone functions, following the constructive approach to analysis developed in [4].

Brouwer [5] has proposed intuitionistic proofs for both statements; an exposition may be found in [7]. However, the proofs are based on methods not constructive in the sense adopted here.

Recursive analysis offers a proof for the first statement [11] [6] [8], and a counterexample to the second [9]; expositions appear in [1]. However, the first result is based on a nonconstructive hypothesis, and both results are based on an interpretation of real numbers as recursive real numbers, an interpretation more restrictive than is appropriate for constructive analysis.

Metamathematical results concerning the consistency and independence of the continuity statements, in intuitionistic formal systems, are found in [2] and [3].

Here we follow a direct mathematical, rather than metamathematical, approach, using no formal system, under no special hypotheses, and with no preconceived notions about the nature of the continuum, other than that it consists of constructively defined Cauchy sequences of rational numbers. 
1. Preliminaries. Throughout the paper, function will mean a real-valued function on the closed unit interval $[0,1]$; and $x, y, z$ will denote points of the interval. Only constructive properties of the real numbers, such as are found in [4], will be admitted.

A function $f$ is said to be increasing if $x<y$ implies $f(x)<f(y)$, while $f$ is nondecreasing if $x \leqq y$ implies $f(x) \leqq f(y)$. While classically one has but these two main notions of monotonicity, under constructive scrutiny other distinctions come into view.

We say that $f$ is antidecreasing if $f(x)<f(y)$ implies $x<y$. Classically, this is equivalent to nondecreasing. Constructively, however, while an antidecreasing function is always nondecreasing, the converse has not been proved. Neither is a counterexample readily at hand, because the converse is true for pointwise continuous functions. Thus a counterexample would entail the construction of a function not pointwise continuous.

A function $f$ attains intermediate values if whenever $f(x) \leqq \lambda \leqq$ $f(y)$, there exists $z$ such that $f(z)=\lambda$, while $f$ approximates intermediate values if whenever $f(x) \leqq \lambda \leqq f(y)$ and $\varepsilon>0$, there exists $z$ such that $|f(z)-\lambda|<\varepsilon$. It is noted in [4] that a uniformly continuous function approximates intermediate values. If we construct a function $f$ and numbers $x, y, \lambda$ and $\varepsilon>0$ such that $f(x) \leqq \lambda \leqq f(y)$, and prove that there does not exist $z$ such that $|f(z)-\lambda|<\varepsilon$, then we will have partitioned the real line into two nonvoid disjoint subsets; as yet such a partition has never been constructed.

A crucial step in the proof that a monotone pointwise continuous function is uniformly continuous requires the following theorem [12], which is of interest not merely for monotone functions. The author is grateful for the communication of this result.

THEOREM (Mines-Richman). A pointwise continuous function approximates intermediate values.

Proof. Let $f(x) \leqq \lambda \leqq f(y)$ and $\varepsilon>0$. Since $f$ is pointwise continuous, the sets $U \equiv\{z: f(z)<\lambda+\varepsilon\}$ and $V \equiv\{z: f(z)>\lambda-\varepsilon\}$ are open. They are also nonvoid and cover the interval. Theorem 2 in [10] shows that any two nonvoid open sets which cover the interval have a common point. For any point $z$ common to $U$ and $V$, clearly $|f(z)-\lambda|<\varepsilon$.

2. Pointwise and uniform continuity. It is a simple exercise to show that an increasing function is nondecreasing; thus the following applies also to increasing functions.

THEOREM 1. For any nondecreasing function $f$, the following 
are equivalent.

(a) $f$ is antidecreasing and approximates intermediate values.

(b) $f$ is pointwise continuous.

(c) $f$ is uniformly continuous.

Proof. (a) implies (b). Consider any $x$ and any $\varepsilon>0$. If $f(x)<$ $f(0)+\varepsilon$ then $f(y)>f(x)-\varepsilon$ for all $y$. Thus we may assume $f(x)>$ $f(0)$ and similarly $f(x)<f(1)$. Construct $y$ and $z$ so that $f(x)-\varepsilon<$ $f(y)<f(x)$ and $f(x)<f(z)<f(x)+\varepsilon$; thus $y<x<z$. The open interval $(y, z)$ is the required neighborhood of $x$.

(b) implies (a). It sufficies to show that $f$ is antidecreasing. Let $f(x)<f(y)$. Put $\varepsilon \equiv f(y)-f(x)$ and $\delta \equiv \omega(x, \varepsilon)$, where $\omega$ is a modulus of continuity for $f$. Since $|x-y|<\delta$ involves a contradiction, we have $|x-y|>0$ and thus $x<y$.

(b) implies (c). Let $\varepsilon>0$ and construct a finite $\varepsilon / 6$ approximation $A$ to the interval $[f(0), f(1)]$. For each $\alpha$ in $A$, construct $z_{\alpha}$ such that $\left|f\left(z_{\alpha}\right)-\alpha\right|<\varepsilon / 6$. Put

$$
\delta \equiv \min \left\{\omega\left(z_{\alpha}, \varepsilon / 2\right): \alpha \in A\right\} .
$$

Let $|x-y|<\delta$. In the case $|f(x)-f(y)|<\varepsilon$ there is nothing more to prove; thus we need consider only the case $|f(x)-f(y)|>2 \varepsilon / 3$. We may assume $f(x)<f(y)$. Let $\mu$ be the midpoint of $f(x)$ and $f(y)$ and construct $\alpha$ in $A$ such that $|\alpha-\mu|<\varepsilon / 6$. Then $\left|f\left(z_{\alpha}\right)-\mu\right|<$ $\varepsilon / 3$ and thus $f(x)<f\left(z_{\alpha}\right)<f(y)$. It follows that $x \leqq z_{\alpha} \leqq y$ and thus $\left|x-z_{\alpha}\right|<\delta$. Hence $\left|f(x)-f\left(z_{\alpha}\right)\right|<\varepsilon / 2$ and similarly for $f(y)$. Thus $|f(x)-f(y)|<\varepsilon$.

Furthermore, it is easily seen that if a function $f$ is nondecreasing and sequentially continuous (i.e., $x_{n} \rightarrow x$ implies $f\left(x_{n}\right) \rightarrow$ $f(x)$ ), then $f$ is pointwise (and hence uniformly) continuous. In general, it is not known whether every sequentially continuous function is pointwise continuous.

3. Totally bounded sections. For any real number $\alpha$, the $\alpha$ section of a function $f$ is

$$
X_{\alpha} \equiv\{x: f(x) \leqq \alpha\} .
$$

In order to construct inverse functions, we first show that an increasing function has totally bounded sections.

A general lemma on totally bounded sets is required. For any set $F$ in a metric space $X$, and any $\varepsilon>0$, put

$$
F^{\varepsilon} \equiv \bigcup_{a \in F} S(a, \varepsilon)
$$


where $S(a, \varepsilon)$ is the open sphere in $X$ with center $a$ and radius $\varepsilon$. For any subset $S$ of $X$, put

$$
S^{*} \equiv\{a \in X: a \notin S\}
$$

where $a \notin S$ means that $a \in S$ involves a contradiction.

Lemma. Let $X$ be a totally bounded metric space and $F$ a nonvoid subset of $X$. Then $F$ is totally bounded if and only if for any $\varepsilon>0$ there exists $\delta>0$ such that

$$
X=F^{\varepsilon} \cup F^{i *} .
$$

Proof. First let $F$ be totally bounded. Let $\varepsilon>0$ and put $\delta \equiv \varepsilon / 2$. For any point $a$ in $X$, the distance $\rho(a, F)$ exists. If $\rho(a, F)<\varepsilon$ then $a \in F^{\varepsilon}$, while if $\rho(a, F)>\delta$ then $a \notin F^{\delta}$.

Conversely, for any $\varepsilon>0$ we will construct a subfinite $2 \varepsilon$ approximation to $F$. Choose $\delta>0$ so that $X=F^{\varepsilon} \cup F^{j *}$ and $\delta<\varepsilon$. Construct a finite $\delta$ approximation $A$ to $X$. Partition $A$ into two sets $A_{1}$ and $A_{2}$ so that $A_{1} \subseteq F^{\varepsilon}$ and $A_{2} \subseteq F^{\delta *}$. For each $a$ in $A_{1}$ construct $a^{\prime}$ in $F$ such that $\rho\left(a, a^{\prime}\right)<\varepsilon$, and put $A^{\prime} \equiv\left\{a^{\prime}: a \in A_{1}\right\}$. To show that $A^{\prime}$ is the required approximation to $F$, consider a point $b$ in $F$ and construct $a$ in $A$ such that $\rho(b, a)<\delta$. Then $a \in F^{\delta}$; it follows that $a \in A_{1}$ and hence $\rho\left(b, a^{\prime}\right)<2 \varepsilon$.

THEOREM 2. If a function $f$ is increasing, then its sections $X_{\alpha}$ are totally bounded for all $\alpha \geqq f(0)$.

Proof. Let $\varepsilon>0$ and put $\delta \equiv \varepsilon / 2$. Consider any point $x$. When $x<\varepsilon$ we have $x \in X_{\alpha}^{\varepsilon}$ because $0 \in X_{\alpha}$. Thus we may assume $x>\delta$ and construct $y$ so that $x-\varepsilon<y<x-\delta$. Thus $|x-y|<\varepsilon$. Also, $f(y)<f(x-\delta)$; it follows that either $\alpha<f(x-\delta)$ or $\alpha>f(y)$. In the first case $x \notin X_{\alpha}^{\delta}$, while in the second case $y \in X_{\alpha}$ and hence $x \in X_{\alpha}^{\varepsilon}$.

EXAMPLE. It is not constructively true that every nondecreasing function has all its sections totally bounded. For, suppose it were true and let $\alpha \geqq 0$. Put $f(x) \equiv \alpha x$ for all $x$. Then $f$ is nondecreasing; put $y \equiv \sup X_{0}$. In the case $y>0$ it follows that $\alpha=0$, while in the case $y<1$ it follows that not $\alpha=0$. Thus under our hypothesis it follows that for any $\alpha \geqq 0$, either $\alpha=0$ or not $\alpha=0$. This last statement, a form of the weak limited principle of omniscience, is not constructively true. This type of counterexample is discussed further in [4].

4. Inverse functions. An inverse of an increasing function $f$ 
will mean an inverse defined on the interval $[f(0), f(1)]$.

THEOREM 3. For any increasing function $f$, the following are equivalent.

(a) $f$ approximates intermediate values.

(b) $f$ attains intermediate values.

(c) $f$ has an inverse.

Proof. (a) implies (b). Let $f(0) \leqq \alpha \leqq f(1)$. By Theorem 2, $X_{\alpha}$ is totally bounded; put $x \equiv \sup X_{\alpha}$. First suppose $f(x)>\alpha$ and construct $y$ such that $\alpha<f(y)<f(x)$; then $y=x$. If $y<x$ then $y<z$ for some $z \in X_{\alpha}$, a contradiction; thus $y=x$ and this is a contradiction. Now suppose $f(x)<\alpha$ and construct $y$ such that $f(x)<f(y)<\alpha$; then $x \leqq y$. Also $y \in X_{\alpha}$, so that $y \leqq x$; hence $x=y$, a contradiction. It follows that $f(x)=\alpha$.

(b) implies (c). Put $X \equiv[0,1]$ and $Y \equiv[f(0), f(1)]$. For any $\alpha$ in $Y$ construct $x_{\alpha}$ in $X$ such that $f\left(x_{\alpha}\right)=\alpha$. If $\alpha=\beta$ then $x_{\alpha}=x_{\beta}$ because $f$ increases. Thus $g(\alpha) \equiv x_{\alpha}$ defines a function $g: Y \rightarrow X$ such that $f(g(\alpha))=\alpha$ for all $\alpha \in Y$. Since $f$ increases, it follows that $g(f(x))=x$ for all $x \in X$. Hence $g$ is the inverse of $f$.

THEOREM 4. An increasing pointwise (hence uniformly) continuous function has an increasing uniformly continuous inverse.

Proof. The given function $f$ is antidecreasing by Theorem 1; thus the inverse $g$ is increasing. Clearly $g$ is antidecreasing and attains intermediate values; it follows from Theorem 1 that $g$ is uniformly continuous.

\section{REFERENCES}

1. O. Aberth, Computable Analysis, McGraw-Hill, New York, 1980.

2. M. Beeson, The unprovability in intuitionistic formal systems of the continuity of effective operations on the reals, J. Symbolic Logic, 41 (1976), 18-24.

3. M. Beeson, Principles of continuous choice and continuity of functions in formal systems for constructive mathematics, Ann. Math. Logic, 12 (1977), 249-322.

4. E. Bishop, Foundations of Constructive Analysis, McGraw-Hill, New York, 1967.

5. L. E. J. Brouwer, Beweis, dass jede volle Funktion gleichmässig ist, Proc. Akad. Amsterdam, 27 (1924), 189-194.

6. G. S. Ceitin, Alhorithmic operators in constructive complete separable metric spaces. Dokl. Akad. Nauk SSSR, 128 (1959), 49-52 (Russian).

7. A. Heyting, Intuitionism, an introduction, 3rd ed., North-Holland, Amsterdam, 1971.

8. G. Kreisel, D. Lacombe and J. R. Shoenfield, Fonctionnelles récursivement définissables et fonctionnelles récursives, C.R. Acad. Sci. Paris Sér. A-B, 245 (1957), 399-402.

9. D. Lacombe, Remarques sur les opérateurs recursifs et sur les fonctions recursives d'une variable réelle, C.R. Acad. Sci. Paris Sér. A-B, 241 (1955), 1250-1252.

10. M. Mandelkern, Connectivity of an interval, Proc. Amer. Matn. Soc., 54 (1976), 170-172. 
11. A. A. Markov, On the continuity of constructive functions, Uspehi Mat. Nauk.,' 9 (1954), 226-230 (Russian).

12. R. Mines and F. Richman, informal communication, August 1978.

Received September 3, 1980 and in revised form February 11, 1981. 


\title{
PACIFIC JOURNAL OF MATHEMATICS
}

\section{EDITORS}

\author{
DONALD BABBITT (Managing Editor) \\ University of California \\ Los Angeles, CA 90024 \\ Hugo RossI \\ University of Utah \\ Salt Lake City, UT 84112 \\ C. C. MOORE and Arthur Agus \\ University of California \\ Berkeley, CA 94720
}

\section{J. DugundjI}

Department of Mathematics

University of Southern California

Los Angeles, CA 90007

R. FinN and J. Milgram

Stanford University

Stanford, CA 94305

\section{ASSOCIATE EDITORS}
R. ARENS
E. F. BeCKENBACH
B. H. NeumanN
F. WOLF
K. YoshidA

\section{SUPPORTING INSTITUTIONS}

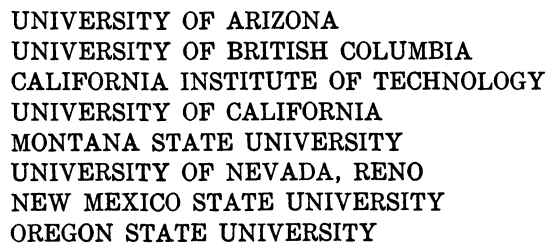

UNIVERSITY OF ARIZONA

UNIVERSITY OF BRITISH COLUMBIA

CALIFORNIA INSTITUTE OF TECHNOLOGY

UNIVERSITY OF CALIFORNIA

MONTANA STATE UNIVERSITY

UNIVERSITY OF NEVADA, RENO

NEW MEXICO STATE UNIVERSITY

OREGON STATE UNIVERSITY

\author{
UNIVERSITY OF OREGON \\ UNIVERSITY OF SOUTHERN CALIFORNIA \\ STANFORD UNIVERSITY \\ UNIVERSITY OF HAWAII \\ UNIVERSITY OF TOKYO \\ UNIVERSITY OF UTAH \\ WASHINGTON STATE UNIVERSITY \\ UNIVERSITY OF WASHINGTON
}

The Supporting Institutions listed above contribute to the cost of publication of this Journal, but they are not owners or publishers and have no responsibility for its content or policies.

Mathematical papers intended for publication in the Pacific Journal of Mathematics should be in typed form or offset-reproduced, (not dittoed), double spaced with large margins. Please do not use built up fractions in the text of the manuscript. However, you may use them in the displayed equations. Underline Greek letters in red, German in green, and script in blue. The first paragraph or two must be capable of being used separately as a synopsis of the entire paper. Please propose a heading for the odd numbered pages of less than 35 characters. Manuscripts, in triplicate, may be sent to any one of the editors. Please classify according to the scheme of Math. Reviews, Index to Vol. 39. Supply name and address of author to whom proofs should be sent. All other communications should be addressed to the managing editor, or Elaine Barth, University of California, Los Angeles, California, 90024.

50 reprints to each author are provided free for each article, only if page charges have been substantially paid. Additional copies may be obtained at cost in multiples of 50 .

The Pacific Journal of Mathematics is issued monthly as of January 1966. Regular subscription rate: $\$ 102.00$ a year (6 Vols., 12 issues). Special rate: $\$ 51.00$ a year to individual members of supporting institutions.

Subscriptions, orders for numbers issued in the last three calendar years, and changes of address shoud be sent to Pacific Journal of Mathematics, P.O. Box 969, Carmel Valley, CA 93924, U.S.A. Old back numbers obtainable from Kraus Periodicals Co., Route 100, Millwood, NY 10546.

\section{PUBLISHED BY PACIFIC JOURNAL OF MATHEMATICS, A NON-PROFIT CORPORATION}

Printed at Kokusai Bunken Insatsusha (International Academic Printing Co., Ltd.). 8-8, 3-chome, Takadanobaba, Shinjuku-ku, Tokyo 160, Japan. 


\section{Pacific Journal of Mathematics}

Vol. 99, No. $2 \quad$ June, 1982

Thomas E. Armstrong and Karel Libor Prikry, On the semimetric on a

Boolean algebra induced by a finitely additive probability measure . . . .249

Walter Russell Bloom, Strict local inclusion results between spaces of

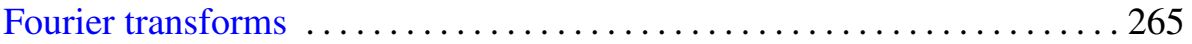

Richard Clark Brown, Notes on generalized boundary value problems in

Banach spaces. II. Infinite-dimensional extension theory ........... 271

Sui Sun Cheng, Isoperimetric eigenvalue problem of even order differential

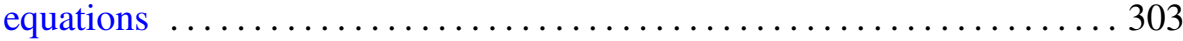

Lung O. Chung and Jiang Luh, Derivations of higher order and

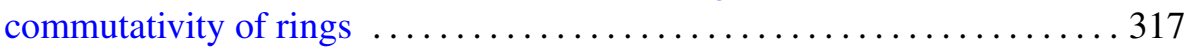

Ali Ahmad Fora, A fixed point theorem for product spaces . . . . . . . . . 327

Barry J. Gardner, Radical classes of regular rings with Artinian primitive

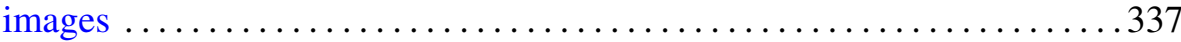

John Brady Garnett and Peter Wilcox Jones, BMO from dyadic BMO . . . 351

Allen E. Hatcher, On the boundary curves of incompressible surfaces . . . . 373

Richard Howard Hudson and Kenneth S. Williams, Resolution of

ambiguities in the evaluation of cubic and quartic Jacobsthal sums .....379

Viktor Losert, Counter-examples to some conjectures about doubly

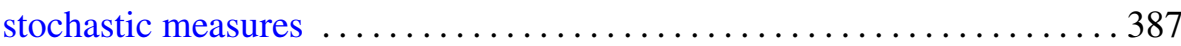

Kenneth Derwood Magill, Jr., P. R. Misra and Udai Bhan Tewari,

Structure spaces for sandwich semigroups

Mark Mandelker, Continuity of monotone functions

Kenneth Guy Miller, An index theorem and hypoellipticity on nilpotent Lie groups ......................................... 419

Evelyn M. Nelson, Homomorphisms of mono-unary algebras . . . . . . . . . 427

Marvin E. Ortel, The support of an extremal dilatation . . .

R. S. Pathak and O. P. Singh, Finite Hankel transforms of distributions . . . 439

Richard Cole Penney, The theory of ad-associative Lie algebras

Linda Ruth Sons, Zero distribution of functions with slow or moderate

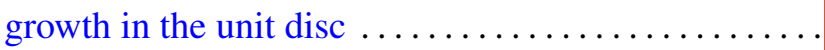

Russell Bruce Walker, Transversals to laminations 